\title{
Enunciación
}

http://revistas.udistrital.edu.co/ojs/index.php/enunc

DOI: http://dx.doi.org/10.14483/udistrital.jour.enunc.2015.1.a07

\section{Del paradigma alfabetizador a los lugares enunciativos sobre la alfabetización}

\author{
From the literacy paradigm to the statement places about literacy \\ Yeison Alberto Laiton Pérez ${ }^{1}$
}

Para citar este artículo: Laiton, Y. A. (2015). Del paradigma alfabetizador a los lugares enunciativos sobre la alfabetización. Enunciación, 20(1), pp. 94-108.

Recibido: 30-abril-2015 / Aprobado: 22-junio-2015

\section{Resumen}

El propósito de esta reflexión es plantear que cualquier concepto de alfabetización juega un papel estratégico dentro de cada cultura al encargarse de potenciar o disminuir tanto los efectos sociales producidos por unos discursos como los recursos materiales sobre los cuales estos adquieren su significación. Se pretende analizar algunos elementos, que desde una mirada decolonial, permiten problematizar los enfoques contemporáneos sobre la escritura y la lectura en la educación. Según esta aproximación, en Occidente existe un monopolio sobre el saber acerca del alfabetismo, que dejaría la diversidad de posibilidades de lectura y escritura diversas en desventaja frente a un diálogo de saberes. La teoría del discurso multimodal y las reflexiones de la pedagogía de las multialfabetizaciones amplían la escritura centrada en el lenguaje gráfico-alfabético para dar cabida a otras posibilidades de significación. Teniendo en cuenta las demandas de equidad en nuestras sociedades, resultaría inadecuado referirse a la alfabetización como un concepto universalmente válido.

Palabras clave: alfabetización, multimodalidad, teoría decolonial, educación, interculturalidad.

\begin{abstract}
The goal of this reflection is to lay out that any concept of literacy plays a strategic role inside any culture as it is responsible of strengthening or reducing the social effects produced by some discourses, as well as the material resources that support them. This article expects to analyze some elements that allow to make problematic the contemporary approaches about reading and writing in education, from a decolonial view. From this perspective, in Western society exists a monopoly over the knowledge about literacy, this situation would let the diversity of possibilities of reading and writing at a disadvantage in a dialogue of knowledges. The multimodal discourse theory and the reflections of pedagogy of multiliteracies blow up the writing centered in the graph-alphabetic language to make space for other meaning possibilities. Considering the requests of equity in our societies, it would be inappropriate to refer to literacy as a universally accepted concept.
\end{abstract}

Keywords: Literacy, multimodal discourse, decolonial theory, education, interculturality.

1 Estudiante de la Licenciatura en Educación Básica con Énfasis en Humanidades y Lengua Castellana de la Universidad Distrital Francisco José de Caldas. Adscrito al Grupo de Investigación Lenguaje, Cultura y Medios (LECME). Correo electrónico: jalaitonp@correo.udistrital.edu.co 


\section{INTRODUCCIÓN}

El objetivo en este texto es proponer una mirada crítica de la lectura y la escritura con el fin de resaltar la necesidad de encarar proyectos pedagógicos de alfabetización en donde se comprendan variados lenguajes y se reconozcan los entornos culturales donde se desenvuelven. Tradicionalmente se ha vinculado la alfabetización con la adquisición del código lingüístico, de alguna lengua oficial, a través de la escritura alfabética; perspectivas recientes tratan de ensanchar este concepto, o en casos más radicales proponer uno propio, con el fin de dar cabida a otros fenómenos de comunicación humana. La inestabilidad entre los límites propuestos para una alfabetización y el rango de los fenómenos que se presentan cotidianamente en las escuelas ha llevado a la ambigüedad generalizada de las múltiples propuestas, ha desdibujado el concepto inicial que se centraba en la grafía y lo ha expandido a otros lenguajes, como en el caso del alfabetismo funcional o el alfabetismo cultural. A tal punto se ha acrecentado su utilización que es muy difícil poder demarcar claramente dónde comienza una propuesta $X$ y termina otra $Y$; esto es un agravante para el educador, pues debe pensar en conciliar las finalidades de conceptos distintos que se supone hablan de lo mismo (Hernández, 2008). Sin embargo, esta reflexión intentará explicar desde una postura relativista que esta tendencia centrífuga obedece a la necesidad de reconocer en toda propuesta de alfabetización la existencia de lugares de enunciación sociohistóricos, cuya influencia está determinada por la pertinencia que representa para los grupos humanos a los cuales se dirige.

Lo anterior se pretende encarar mostrando cómo el carácter universal del paradigma alfabético arraigado (centrado en la grafía) ha venido siendo cuestionado desde diversos campos interdisciplinares en las últimas décadas, lo cual hace insostenible tratar de menospreciar otras maneras de ser alfabetizado en la contemporaneidad, si pensamos en una sociedad radicalmente democrática.
Para esto es necesario explicar de qué manera la teoría de los multialfabetismos, en tanto posibilidad de reconocer los discursos y prácticas concretas de alfabetización, permite acercarse a los significados culturales propios de cualquier comunidad; también, cómo sirve para reconocer otras maneras de leer, escribir y comprender el mundo en el horizonte educativo, facilitando el diálogo intercultural.

Para ello, primero se retomarán algunos principios analíticos ofrecidos por la teoría decolonial y con ellos hará una crítica al papel hegemónico de la escritura alfabética, pues se creyó que todos los demás códigos siempre le fueron subsidiarios e inclusive menos valiosos, inferiores en lo referente a sus posibilidades comunicativas. Es necesario reconocer que la escritura alfabética continúa teniendo una gran dignidad, pues desde hace tiempo es usual considerarla como uno de los pilares sobre los cuales Occidente se erigió como una de las civilizaciones, culturalmente, más "avanzadas". Según tales principios, otros códigos debieron ser vistos como menos científicos, menos modernos y más simples: lo cual sería prueba indiscutible del atraso y la barbaridad de las otras sociedades.

El siguiente paso será exponer en perspectiva genealógica los elementos de la alfabetización indagados por los diversos investigadores sociales y enseñar la fractura que se da en el paso a la pedagogía de las multialfabetizaciones y el discurso multimodal, de carácter relativista y múltiple, frente a "la alfabetización" como paradigma rígido y oficial. Varios autores se han acercado a diferentes etnias y los resultados de sus indagaciones ponen en cuestión la supuesta supremacía científica, estética y democrática de la escritura alfabética: se mostrará el surgimiento de diversas hipótesis cuya influencia aporta a la tesis de una alfabetización contemporánea descentralizada del alfabeto.

La producción intelectual de las escuelas inglesa-norteamericana y brasileña sirve para elaborar un concepto más amplio, o si se quiere, incluyente, de alfabetización para las comunidades de América: si en un principio se concibió al alfabeto como 
un sujeto equipado con la habilidad para el manejo funcional del código escrito alfabético, ahora se propone que este sea un entendido en los discursos de su cultura y los soportes materiales a través de los cuales estos circulan; además de estar al tanto de la dinámica social de su medio y ser apto para proponer soluciones a problemáticas sociales concretas. Se hablará de la teoría del discurso multimodal y las reflexiones que, desde la pedagogía de los multialfabetismos, consideran la lectura y escritura como prácticas social e históricamente localizadas; mediante un análisis de esta teoría es posible mostrar cómo puede ser útil a la hora de decolonizar prácticas interculturales de lectura y escritura. Finalmente, se evidenciará que para significar tales prácticas es imperativo analizar el sentido social de la lectura y la escritura, pues se debe reconocer en la alfabetización un papel activo como constructora de sociedad, no solamente como la formación de habilidades para manejar cualesquiera códigos lingüísticos o la apropiación de algunos discursos sobre "la" cultura.

\section{HABLAR DE "EL ALFABETISMO" ¿ES UN ETNOCENTRISMO?}

Para empezar se expondrá cuál es proyecto investigativo de los principales teóricos decoloniales y, en seguida, cómo estas preocupaciones concuerdan con las posibilidades que ofrece la teoría de las multialfabetizaciones en tanto permite problematizar y proponer metodologías para la reformulación de las prácticas educativas. Básicamente, son cuatro los referentes nucleares que sirven de hilo conductor a la teoría decolonial: la negación de la coetaneidad del tiempo, la imbricación entre capitalismo y cultura, el diálogo con formas no occidentales de conocer y el pensamiento heterárquico (Castro-Gómez y Grosfoguel, 2007). El primer elemento hace referencia a la arraigada noción antropológica de progreso social, cuya cientificidad sirvió como base a la ingeniería social que implementarían los Estados durante finales del siglo XIX e inicios del XX:
La negación de la simultaneidad epistémica, esto es, la coexistencia en el tiempo y el espacio de diferentes formas de producir conocimientos crea un doble mecanismo ideológico. En primer lugar, al no compartir el mismo tiempo histórico y vivir en diferentes espacios geográficos, el destino de cada región es concebido como no relacionado con ningún otro $^{[2]}$. En segundo lugar, Europa/Euro-Norteamérica son pensadas como viviendo una etapa de desarroIlo (cognitivo, tecnológico y social) más "avanzada" que el resto del mundo, con lo cual surge la idea de superioridad de la forma de vida occidental sobre las demás (Castro-Gómez y Grosfoguel, 2007, p. 15).

Esta creencia ha estado muy arraigada en Occidente, en donde, por supuesto, la escritura cumple un papel fundamental. La lectura y la escritura alfabética occidentales, antiguamente, adquirieron sus principales rasgos como parte del saber de una profesión (en el sentido de oficio), únicamente reservado a los escribas, quienes poseían el conocimiento sobre la técnica de grabado: esto implicaba que al ser técnicos de la escritura, no controlaban el discurso que reproducían, pues este era potestad de las sacras autoridades; el grabado era un trabajo artístico cuyo rigor era aprendido en escuelas especiales para ello (Ferreiro, 2005). Dicha tradición se mantuvo más o menos intacta hasta la invención de la imprenta, que trajo consigo la aparente democratización del acceso a la escritura. Con la Declaración Universal de los Derechos del Hombre, la lectura y escritura pasaron de ser un signo de distinción social a ser una obligación para toda persona que se preciase de ser ciudadana: quien no manejara esta tecnología no podía acceder a los derechos de todo ciudadano (Ferreiro, 2005). Estos dos momentos, de centralismo y democratización, conducen a ver que "los verbos leer y escribir no tienen una definición unívoca. Son verbos que remiten a construcciones sociales,

2 Este mecanismo ideológico hace referencia a la teoría del sistema-mundo moderno colonial. 
a actividades socialmente definidas" (Ferreiro, 2005, p. 41). Aun así, una gran parte de las prácticas del paradigma antiguo se mantuvieron hasta el punto de oscurecer el hecho de que la escritura alfabética es un recurso semiótico igualmente significativo con respecto a otros como el tejido, la pintura, la escultura, la música, la corporalidad y la oralidad. En seguida, con el segundo elemento, se verá cómo Occidente ha creado un culto respecto a la escritura alfabética, y ha legitimado una supuesta superioridad con la cual se han subordinado otras prácticas de escritura igualmente eficientes en comunidades locales ${ }^{3}$.

Este segundo elemento resalta la necesidad de interrelacionar las categorías economicistas y culturalistas que construyeron la teoría del sistema-mundo y las teorías poscoloniales de corte norteamericano, respectivamente. Por un lado, están los postulados de que el sistema capitalista está interrelacionado en un orden global y, por otro, resuenan los razonamientos sobre el papel del lenguaje en la construcción discursiva de lo social que había sido subsumida por la reputación que siempre tuvo el materialismo (Castro-Gómez y Grosfoguel, 2007). Aunque, para los teóricos decoloniales, ambas adolecen de algunas dificultades: los primeros no logran conjurar en su teorización los elementos aportados por los estudios semióticos sobre la cultura, ni los segundos pueden explicar las relaciones coloniales del sistema capitalista de producción a nivel macrosocial; a lo cual la teoría decolonial sí responde entretejiendo, y no derivando, unos y otros procesos (Castro-Gómez y Grosfoguel, 2007). La tesis del sistema-mundo explicaría que el génesis del colonialismo económico, y también el lingüístico, debe buscarse en la expansión imperialista de la Europa moderna y su consolidación mediante la implementación del modo de producción capitalista, con todo el sistema simbólico de poder aparejado a la grafía:

3 Por oposición a la idea de una aldea global interconectada y avasallada de necesidades forrmativas.
[E]ntre los siglos VIII y XIX se usa la escritura romana para escribir en las lenguas vulgares europeas. Este paso fue decisivo porque precisamente las potencias coloniales de los siglos posteriores (Francia, Inglaterra, España y Portugal) se encargaron de llevar el alfabeto romano a los rincones más escondidos del mundo. En efecto, la extensión de la escritura romana a América, África, Asia y Oceanía está determinada por la expansión colonial (Moreno, 2005, p. 48).

En el caso estrictamente educativo se puede ver que la noción de fracaso escolar, o analfabetismo, nació aparejada con la expansión democratizadora de la escuela para los proletarios (factor económico) por parte de las élites letradas (factor cultural), quienes se encargaban — por derecho natural— de domesticar y culturizar al salvaje; bien fuera a través del diagnóstico e intervención de los problemas individuales (años sesenta) o bien fuese mediante la intervención del medio social del individuo, es decir, la cuestión familiar y urbana de las grandes metrópolis (años setenta). Actualmente, el debate intenta definir quiénes son los letrados e iletrados con base en sus habilidades en prácticas reales de lectura y escritura (Ferreiro, 2005). Estará condenado al fracaso quien no maneje los "elementos básicos" que hacen al ciudadano un ser letrado apto para conducirse eficientemente en la sociedad contemporánea: ahora el lector debe, además de interiorizar y reproducir el código, ser capaz de buscar, seleccionar y procesar la información más adecuada para actuar sobre su ambiente inmediato. La imbricación de los mercados nacionales a nivel mundial implica que los gobiernos deberán invertir más en las nuevas tecnologías de la información y la comunicación para mantenerse interconectados, y no perderle pista a las demandas de innovación; esto necesariamente obliga a que los sujetos deban actualizarse no solamente en los viejos métodos de decodificación alfabética, sino también deben darle paso a un alfabetismo en las nuevas TIC (Bawden, 2008). Esto significa que el analfabetismo es un fenómeno surgido del mismo 
concepto de alfabetismo y no un problema preexistente que deba ser resuelto simplemente con un mejor refinamiento de los métodos e instrumentos para abordar la realidad empírica.

El tercer elemento se postula porque, ante esta realidad, "necesitamos encontrar nuevos conceptos y un nuevo lenguaje que dé cuenta de la complejidad de las jerarquías de género, raza, clase, sexualidad, conocimiento y espiritualidad dentro de los procesos geopolíticos, geoculturales y geoeconómicos del sistema-mundo" (Castro-Gómez y Grosfoguel, 2007, p. 17). En otras palabras, debemos estudiar cuidadosamente los contextos sociales e históricos en los cuales surgen las prácticas de lectura y escritura para proponer soluciones que rebasen las limitaciones del alfabetismo grafocéntrico. La inclusión de nuevas prácticas y objetivos representa un gran problema para la alfabetización escolar tradicional, pues se podría argumentar que, a pesar de su novedad, el objeto de esta sigue estando en casi todos los hechos humanos: el deber de la educación ha sido, en los primeros años, potenciar la capacidad de individuo para manejar un código, cuya función cumple la escolarización básica; y luego, en la educación superior, utilizar estos conocimientos para insertar al individuo en el manejo de textos especializados (Olson, 1998). Una de sus consecuencias ha sido la iniciación de una gran "cruzada" contra el analfabetismo y la eventual reformulación de sus limitaciones para implementar cambios en los sistemas educativos. "Durante trescientos años, los occidentales hemos atribuido nuestra supuesta superioridad cultural respecto de nuestros ancestros iletrados, así como respecto de nuestros vecinos no occidentales, a nuestro acceso a un simple artefacto tecnológico: un sistema alfabético de escritura" (Olson, 1998, p. 22). Otra de sus secuelas, y quizá la más Ilamativa, es la serie de creencias y suposiciones que se extrapolaron de estas a los diversos niveles sociales, tanto en la producción científica como la enseñanza escolarizada de las disciplinas: se debe desistir en creer que las técnicas de lectura, escritura y las de operaciones matemáticas (saberes indispensables de cualquier alfabeto) cumplen un papel transformador por sí mismas (Olson, 1998).

Por la importancia de su crítica al sentido tradicional de la escritura, nos detendremos un poco para examinar estas tesis. David Olson (1998) propone seis mitos acerca del grafocentrismo, como es Ilamado este prejuicio, sobre los cuales la alfabetización erigió toda su estructura conceptual y dio como resultado la determinación de las "buenas prácticas" para la escolarización de la humanidad. El primero es aquel en el cual se dice que la escritura es la transcripción del habla, cuya suposición se basa en que todo texto alfabético escrito puede ser vocalizado: sin embargo, se olvida que gran parte de la potencialidad expresiva del mensaje, y del texto, queda excluido de la escritura y por tanto no es un simple reflejo de la oralidad. El segundo mito es el que afirma la superioridad de la escritura respecto del habla: la escritura es un símbolo de precisión y poder que debe ser aprendido para corregir la imprecisión y desorden de la lengua escrita. Los gramáticos heredaron esta concepción al comparatismo y también a cierta tradición de la lingüística, que debió encasillar la riqueza estructural del lenguaje en las fórmulas más estables de la lengua escrita para su análisis y no porque esto significara una descripción más auténtica.

El tercer mito es la superioridad tecnológica del sistema alfabético de escritura que se le atribuye al genio de Grecia y Roma: según este mito, la correspondencia sonido-grafía es uno de los mayores logros de evolución cultural en la antigüedad y sirvió para diferenciar a los pueblos civilizados de los bárbaros, como los chinos, egipcios o mesoamericanos. Todos aquellos poseedores de sistemas de escritura silábica y pictográfica no serían otra cosa que diferentes estadios intermedios en el camino hacia la escritura alfabética, manifestaciones de subdesarrollo o estadios prealfabéticos. El cuarto mito es el de la escritura alfabética como órgano de progreso social, pues alto nivel de alfabetización es sinónimo de vigorosas instituciones 
sociales y democráticas; el analfabetismo (como el del "Tercer Mundo") es un peligro equiparable a una plaga que se expande por toda la sociedad: a pesar de estas aseveraciones, investigadores demuestran que la escritura ha servido más como un recurso de dominación, pues "los pedidos recientes de mejoras en las habilidades básicas, tanto en Canadá como en Estados Unidos y Gran Bretaña, provienen en su mayor parte de empleadores del ámbito de los negocios o la industria antes que de los propios trabajadores" (Olson, 1998, p. 30). El quinto mito es la escritura como instrumento de desarrollo cultural y científico que tiende a creer en la deuda de la filosofía, la ciencia, la justicia y la medicina, hacia la escritura; todo lo demás es superstición, mitología, magia. No obstante, los estudios antropológicos han demostrado que existen culturas orales igualmente sofisticadas y eso, por ende, polemiza la relación directamente proporcional establecida entre desarrollo científico y escritura.

Finalmente, el sexto mito afirma que la cultura escrita es un instrumento de desarrollo cognitivo, del mismo modo en que lo era del desarrollo cultural; por tanto, el conocimiento legítimo solamente puede ser construido tanto por medio de los libros como en el espacio privilegiado para ello, esto es, la escuela. Pero, "El conocimiento puede comunicarse de diversas maneras: mediante el habla, la escritura, gráficos, diagramas, cintas de audio, videos. El papel de la escuela no es desplazar las percepciones y creencias del niño en edad preescolar, sino explicarlas y elaborarlas" (Olson, 1998, pp. 32-33) recurriendo a otros medios para la significación.

El cuarto elemento aportado por la teoría decolonial, pensamiento heterárquico, consiste en

un intento por conceptualizar las estructuras sociales con un nuevo lenguaje que desborda el paradigma de la ciencia social eurocéntrica heredado desde el siglo XIX. El viejo lenguaje es para sistemas cerrados, pues tiene una lógica única que determina todo lo demás desde una sola jerarquía de poder. (Castro-Gómez y Grosfoguel, 2007, p. 18).

El presente texto centra sus esfuerzos en este último elemento, pues propone nominar otros fenómenos no considerados como escritura en el paradigma grafocéntrico. La delimitación de estos nuevos objetos parte de una crítica producida desde los estudios de campo cuyos resultados han deshecho lo que Brian Street Ilama "the illiterate prejudice" (Street, 2009). Con el desvanecimiento de este prejuicio, las investigaciones han dado una renovada envergadura a problemas otrora resueltos, aparentemente. Estos estudios apuntan en cinco direcciones sobre las cuales se podría profundizar el estudio de los alfabetismos contemporáneos (Hull y Hernández, 2008):

1. Historia del alfabetismo: a) genealogía: continuidades y discontinuidades; b) estudio de los contextos de prácticas de lectura y escritura.

2. Tecnologías de la palabra: a) transformación de la oralidad en otros actos comunicativos (libros, computadores, pinturas, etc.).

3. Alfabetismos a través de culturas y lenguajes: a) diversidades de práctica; b) aprendizaje de lenguas y globalización.

4. Alfabetismo y desarrollo: a) naturaleza del aprendizaje en los niños: b) recursos humanos.

5. Investigación/práctica: a) New London Group: pedagogías multimodales; b) uso de un alfabetismo descontextualizado.

La etnografía del alfabetismo, disciplina en la cual se inscriben dichos trabajos de campo, es un enfoque investigativo que aporta valiosa evidencia para la desnaturalización de las prácticas y discursos comúnmente aceptados mostrando su cara colonial y etnocentrista. Mike Baynham clasifica en tres las generaciones más importantes de la etnografía del alfabetismo: a) primera generación: Street, Scribner y Cole y Heath; b) segunda generación Prinsloo y Breier, Besnier, Kulick y Stroud, Barton y Hamilton; y c) tercera generación Baynham, 
Maddox y Hull y Schultz (Street, 2009). La primera orienta su atención hacia la pedagogía de la alfabetización en contextos educativos; la segunda intenta definir el alfabetismo en un periodo donde irrumpen los textos y discursos multimodales; y la tercera se enfoca en desentrañar cómo y por qué algunos diseños locales han pasado a ser imperativos globales: esto se hace a través del estudio de las alfabetizaciones y tensiones entre estas que se producen en la escuela, los potenciales semióticos de los textos multimodales y la exploración de otros alfabetismos fuera de la escuela que puedan ayudar en el proceso educativo (Street, 2009).

Sin embargo, la etnografía del alfabetismo en su enfoque descriptivo, por sí sola, no explica cómo se puede negociar el significado en una sociedad democrática e intercultural. Así las cosas, es preciso centrar la atención en uno de sus enfoques entre cuyos requisitos se encuentre el tener mecanismos para poder explicar cómo es posible la comunicación mediante diversos lenguajes sin discriminarlos negativamente; $y$, asimismo, de qué manera se puede potenciar la equidad cultural mediante la transformación de la práctica educativa. A continuación se muestra cómo la teoría del discurso multimodal y la pedagogía de los multialfabetismos satisfacen estas condiciones.

\section{GENEALOGÍA DE LOS MULTIALFABE- TISMOS}

El carácter sintético ofrecido por la pedagogía de las multialfabetizaciones se reconocerá mediante un análisis histórico de los estudios sobre el alfabetismo, el cual permitirá detallar en qué medida esta ofrece una concepción holística e inclusiva de diversas alfabetizaciones. Metodológicamente, la genealogía sirve para reconsiderar la visión historicista que se tuvo sobre el alfabetismo por mucho tiempo, además, permite mostrar la coexistencia de diversas teorías con desarrollos paralelos y algunos puntos de contacto o divergencia que aportan elementos para construir proyectos de alfabetización culturalmente situados. De las tres tradiciones investigativas esbozadas, ampliaremos el enfoque multimodal por tratarse del más adecuado a las necesidades propuestas al inicio de este escrito: plantear algunos elementos para una teoría de la alfabetización desde una mirada decolonial. Un autor que sintetiza este recorrido es Brian Street, quien clasifica tres grandes tradiciones en las cuales se agrupan los significados posibles para encaminarse en estudios sobre los alfabetismos (literacy studies). Se contrastarán estas investigaciones con las que se realizaron para dar forma al concepto de letramento, en Brasil, cuya importancia vale la pena resaltar por razones de índole histórica y política.

La primera tradición, dice Street, se caracteriza por referirse al alfabetismo como un aprendizaje individual que puede ser desarrollado independientemente de los factores contextuales, entre sus teóricos más destacados encontramos a Adams y Snow (Street, 2009). La segunda tradición señala que el alfabetismo está determinado por las relaciones sociales de los contextos donde ocurren las prácticas de lectura y escritura; entre sus representantes destacados están Scribner y Cole, Street y Rogers. Este segundo programa investigativo obtuvo gran parte de su fundamentación en trabajos de antropólogos y psicólogos que intentaron explicar cómo aprendían los grupos humanos, y cómo los roles sociales se convertían en objeto de aprendizaje. Aunque la comunidad científica, desde ese entonces, nunca ha tenido criterios unívocos, Street (2009) los clasifica como formalistas y relativistas. La tercera gran tradición intenta superar este dualismo (así como la teoría decolonial hace lo propio) y se enmarca en los estudios multimodales cuya base es la semiótica social de Halliday. Esta escuela propone hablar de múltiples alfabetizaciones y sus representantes destacados son Cope y Kalantzis y Van Leeuwen y Kress (Street, 2009). La alfabetización multimodal tiene dos vertientes: la primera propuesta, de Cope y Kalantzis, caracteriza diversos alfabetismos, entendidos como la adopción de diferentes habilidades para desentrañar, comprender y producir diversos textos, de acuerdo con una tipología socialmente establecida (Bautista, 2007). 
Por otro lado, el New London Group, que constituye un segundo enfoque, enriquece esta clasificación con base en dos supuestos fundamentales: el alfabetismo es una práctica social y política; y, a su vez, se desenvuelve mediante comunicación multimodal (Hull y Hernández, 2008). Se puede decir que las investigaciones sobre el alfabetismo durante los últimos treinta años se han caracterizado por conseguir mayor transitoriedad, fluidez y promoción de la multiplicidad, hasta el punto de referirse a multialfabetismos. Estos últimos dependen de las prácticas sociales en donde se produce significado y de las herramientas tecnológicas o materiales a la mano que permitan hacerlo circular por la comunidad. Para Williams (2004, citado en Hull y Hernández, 2008) hay dos tipos de práctica social: las de dominio estrecho que se identifican a menudo con las habilidades individuales (ámbito privado) de lectura y escritura; y las de dominio amplio (ámbito público) que admiten tener en cuenta el proceso de producción y recepción de los textos como parte de la alfabetización, cuya relación de dependencia se establece con los contextos culturales, sociales e históricos. Los New Literacy Studies, priorizan esta última mirada, mucho más dependiente de la interdisciplinariedad (Gee, 1996; Street, 1993, citados en Hull y Hernández, 2008).

Con el objetivo de ser consecuente con la reflexión decolonial, conviene situar la mirada en el contexto latinoamericano, donde la realidad se ha desenvuelto de una manera particular que marca diferencia con respecto Europa y Norteamérica, cuna de los estudios del discurso multimodal. Brasil es un país donde estas reflexiones han sido muy fructíferas, utilizando el trabajo interdisciplinar desarrollado en ese asunto, adoptando su propio matiz y respondiendo conforme a sus necesidades en el contexto latinoamericano, crearon el término letramento (Soares, 1998). La historia del concepto viene de mucho más atrás, y se dice que procede del inglés literacy. A pesar del origen anglosajón de esta palabra, los brasileños notan que hay diferencias entre uno y otro que se deben explicitar; son importantes en tanto afectan la política y la práctica educativas. En Francia (illettrisme) y Portugal (literacia) el contexto es distinto, porque estos países han tenido altos porcentajes de escolarización; mientras que en Brasil y en Latinoamérica esta fue durante mucho tiempo e incluso recientemente un privilegio de unos pocos (Soares, 2004).

En este orden de ideas, literacy fue evaluado en los países industrializados como la capacidad de hacer cosas con los textos en situaciones concretas, pues se sobreentendía que esta población ya tenía conocimiento del código escrito debido a los altos índices de escolaridad básica, como por ejemplo en Reino Unido o Australia (Soares, 2004). Esta herencia norteamericana y europea se convirtió en un problema pedagógico en las escuelas brasileñas, pues se adoptó toda la teoría de corte cognitivista, descuidando los métodos concretos de lectoescritura alfabética basados en la decodificación lingüística, aunque ambos paradigmas de entrada nunca fuesen incompatibles (Soares, 2004). Lo importante en la diferenciación entre alfabetización (en su visión tradicional) y letramento, que proponen los brasileños, es recordar que a pesar de la necesidad de descentralizar la alfabetización grafocentrista, es evidente que tampoco se puede descuidar la posibilidad de manejar la escritura alfabética; no es razonable ni tampoco opcional imponer otro código para cumplir las mismas funciones coloniales atribuidas a la escritura alfabética. Para las diversas culturas, es poco estratégico ensimismarse en sus escrituras particulares y descuidar sus relaciones con la sociedad globalizada, en caso de que esto pudiera hacerse tan fácilmente; la solución no es implantar forzosamente otro código e institucionalizar prácticas lectoescritoras determinadas para reemplazar las existentes, pues de cierta manera la escritura alfabética es eficiente en ciertos escenarios, mas no en todos ellos. Para ello se propone la alfabetización multimodal como teoría pertinente, pues responde a los problemas planteados en el contexto latinoamericano. 
Recapitulando: en estas líneas se mostró cómo la alfabetización en su perspectiva social recoge una argumentación más inclusiva y abarcadora sobre la formación del sujeto, pues trata de reconocer la existencia de la comunicación en múltiples lenguajes, sin dar primacía a la lengua escrita; y busca explorar una idea de comunicación enriquecida a través de múltiples significados mediante los diversos lenguajes que pueden ser requeridos por un mismo mensaje. A continuación veremos específicamente cuál es la diferencia que marca la pedagogía de los multialfabetismos y el aporte que hace la alfabetización en lenguajes multimodales a una teoría decolonial sobre la alfabetización.

\section{DE LA NOCIÓN DE ALFABETISMO GENERAL HACIA LAS MULTIALFABETIZACIONES EN PERSPECTIVA MULTIMODAL}

La teoría del discurso multimodal y la pedagogía multialfabetizaciones, principalmente desarrolladas por los New Literacy Studies, no solamente explican el proceso de constitución y actuación en escenarios comunicativos, sino que muestra una serie de condiciones fundamentales para un proyecto pedagógico multimodal: la práctica situada, la instrucción pública (el estudiante sabe el qué, el cómo y el porqué se le enseña), un marco crítico y la imperiosa necesidad de transformar las prácticas (New London Group, 1996). En otro apartado, se ejemplificará cómo el discurso multimodal nos permite observar un objeto, v. gr. el tejido andino, como una práctica discursiva concreta, cuya dignidad de escritura fue puesta en cuestión durante mucho tiempo debido a los prejuicios ya anotados antes.

Se debe recordar que la alfabetización es un proceso que define: 1) una tecnología simbólica para representar palabras e ideas mediante signos gráficos, 2) la habilidad para leer tales signos, 3) las prácticas sociales y culturales que surgen alrededor de los usos de tal tecnología y 4) el proceso de conversión en alfabetizado o letrado mediante escolarización formal o informal (Hernández,
2008). Esta definición ampliada es necesaria debido a la gran confusión surgida por la permanente emergencia de nuevos conceptos y características atribuidas al alfabetismo, pues en gran parte las exigencias al medio educativo y la demanda del mercado moldea las necesidades hacia una incesante especialización. Por ejemplo, el estudio de los nuevos lenguajes de la informática y la alfabetización digital nos permite ver que las variables constitutivas en una época mudan a menudo, que se dejan de responder a las necesidades concretas siempre cambiantes; con el paso del tiempo se complejizan y requieren esfuerzos de integración y transposición de las barreras entre disciplinas que expliquen lo que sucede con el lenguaje en estos campos (Bawden, 2008; Manovich, 2005).

A pesar de la heterogeneidad de todas estas propuestas, se puede observar que concuerdan en que debe haber un conocimiento del código escrito específico, la lengua específica del código escrito (es decir, las reglas reguladoras del sistema); el lenguaje social propio para entender ciertos textos; la experiencia práctica que permita hacer de eso unos parámetros y valide la interpretación subjetiva de los textos, esto es, una comunidad de práctica; y la necesidad de manejar ciertos medios y tecnologías para ser alguien alfabetizado (Hernández, 2008). Se debe resaltar en estas definiciones que es la emergencia del contexto de práctica en donde la alfabetización adquiere un sentido pleno, pues, como se ha enfatizado, quiere cambiarse el prejuicio de la alfabetización universal válida para todos los lugares geoculturales y espacios simbólicos.

Conviene recordar que la lingüística aportó a la educación en lenguaje desde dos áreas interdisciplinares diferentes pero complementarias: la psicolingüística y la sociolingüística (Manghi, 2007). Mientras la primera centra su atención en las habilidades lingüísticas innatas, la segunda se enfoca en la actuación patente que se hace con el discurso. La primera es una herencia del generativismo chomskiano, en especial de su aspecto transformacional, que versa acerca de la competencia en las 
reglas de la lengua. La segunda, con enfoque social, nace con Malinowski quien atribuye a la lengua estas propiedades: existencia en tanto se usa, ubicación topológica en el orden social y cultural, y un contexto cultural y situacional que rodea todo acto de enunciación. Firth retomó las enseñanzas de este último, quien fuera su maestro, e intentó darle forma a su propia teoría sobre el contexto; Hymes propone la competencia comunicativa, gracias a la importancia del trabajo de campo, y con esto las ciencias sociales ven nacer la etnografía del habla; Halliday también reflexiona sobre las relaciones entre texto, contexto e interacción: propone hablar de una semiótica social, no para descomponer el signo en sus partes constitutivas, sino para estudiar las redes de significado entre diversos niveles (Manghi, 2007). La semiótica social o lingüística sistémico-funcional permite entender la interacción social en su complejidad, ya no sometida rígidamente a un generativismo formalista o a un funcionalismo/estructuralismo antropológicos.

La corriente inaugurada por Halliday está en consonancia con nuevas perspectivas (lingüística crítica, estudios del discurso y críticos el discurso) que reaccionan contra el positivismo, los estructuralismos y los estudios clásicos sobre la comunicación (Pardo, 2012). El concepto de discurso se vuelve uno de los ejes centrales en la producción de conocimiento y abre paso a la interdisciplinariedad en las ciencias humanas y sociales: el discurso no solamente es palabra escrita o dicha, sino también acciones que son interpretadas, maneras de organizar significados para afectar la cotidianidad social (Pardo, 2012). La globalización y las TIC formulan nuevos recursos semióticos, es decir, instrumentos y materiales disponibles para crear significado que inciden profundamente en la dinámica comunicativa y los modos de representación social, aunque no sean la única o la mejor materia disponible para significar. Los fenómenos discursivos deben ser el objeto de un riguroso análisis que permita explicar cómo la creación de los signos sirve a la estructuración de esquemas cognitivos: modelos culturales, ideologías y representaciones sociales. Asimismo, cómo se utilizan ciertas modalidades semiodiscursivas para lograr ciertos efectos (Pardo, 2012).

La comunicación multimodal está fundamentada y se adecúa a esta visión, porque va más allá de los límites de la expresión lingüística, una especie de código discreto, y se define como la disponibilidad de variados recursos semióticos para comunicar: existen procesos de comunicación en tanto se pretenda crear significado. Un texto es multimodal cuando en un mismo mensaje se hace uso de más de un recurso semiótico para significar. El academicismo en la cultura escrita ha querido hacer parecer como si el texto escrito abarcara todo el significado, subordinando los demás objetos semióticos a un papel secundario; esta preferencia ha ido perdiendo terreno en la comunicación de la sociedad globalizada (Manghi, 2011; Kress, 2005). La erudición de la palabra escrita es rebasada cuando la semiótica social considera que los recursos semióticos para significar son dependientes de la historia y la cultura. En lugar de hablar de reglas o códigos, es más acertado hacerlo de prácticas y recursos; significa validar cualquier elemento como potencial depositario de significado: la traducción exacta de un código a otro es simplemente imposible, porque es necesario reconocer la diversidad de potencial de significado, o especialización funcional en términos multimodales (Kress, 2005). En esta clase de textos, cada medio aporta una porción de significado y la construcción global queda reservada para el lector (Manghi, 2011). El discurso, más allá de ser un objeto meramente lingüístico establecido al cual se recurre para extraer de allí un significado canónico, es una forma de conocimiento socialmente situado que contiene aspectos formales y culturales (Williamson, 2005).

Williamson (2005) retoma a Kress y Van Leeuwen para explicar cómo es posible que el discurso multimodal funcione como un proceso, con sus respectivos pasos, y no como una entidad terminada en sí: diseño, producción y distribución son los momentos por los cuales atraviesa un conjunto de significados en su discurrir por la sociedad. 
Como se puede ver, los discursos, como los encara la alfabetización multimodal, van más allá del aprendizaje de códigos restringidos. Actualmente, las nuevas tecnologías de la información y la comunicación son el ejemplo más claro de circulación de discursos multimodales: imagen, música y texto integrados en un solo mensaje cuya interpretación depende del conocimiento sobre los lenguajes adscritos a un mensaje y del análisis de contenido de los factores que lo componen.

Esta teoría delimita los objetos de enseñanza de una pedagogía de las multialfabetizaciones con base en la noción de discurso, no en la palabra o la oración, característica fundamental de un proyecto alfabetizador multimodal. El diseño de significado para Kress y Van Leeuwen es una configuración de discursos, a la vez que una interacción entre individuos y una combinación de modos. En otras palabras, un diseño es una selección entre la serie de discursos sobre un saber socialmente construido, cuyo objetivo está determinado por la intención de sus agentes (Williamson, 2005). En la producción de significado, este diseño (ideativo de carácter conceptual y social, retomando los conceptos de Halliday) se vincula con un dispositivo material, esto es, un medio físico y técnico que deviene modo cuando es explotado conscientemente por parte del diseñador. Por ejemplo: quien escoge determinados instrumentos musicales, vientos o cuerdas, para enriquecer la transmisión emocional de una melodía está utilizando ese modo, y no otro, de acuerdo con su conocimiento sobre las posibilidades expresivas de aquellos utensilios. El proceso de diseño y producción puede ser analizado a la luz del sentido real del enunciado, al momento de su distribución en la sociedad (Kress, 2005; Williamson, 2005).

Los recursos semióticos, desde la perspectiva de la semiótica social y el discurso multimodal confluyen en eventos comunicativos a través de medios escritos, digitales, cara a cara, visuales, sonoros, espaciales y proxémicos: es por esto que no debería pensarse en una sola alfabetización, sino en alfabetizaciones múltiples. Aprender un significado es estudiar o comprender cómo se significa una cultura y por ende las formas de pensar su mundo (Manghi et al., 2013). La alfabetización multimodal, y en esto se aleja de la lingüística en estricto sentido, comprende: material escrito, material gráfico, modos corporales y materiales para la construcción de significado; es decir, un modo: "recurso semiótico social y cultural a partir del cual se constituyen significados" (González, 2013, p. 93). En el caso de la enseñanza, los recursos semióticos deben ser analizados con el fin de entender que toda comunicación humana implica una complejidad propia de acuerdo con un sistema de signos y cuya apreciación no siempre está a la mano, o que generalmente requiere de más información (cultural) para ser comprendida.

La alfabetización, una vez trasciende la página, permite la incursión de los lenguajes de la imagen, el sonido, el gesto-movimiento, interacción corporal y el espacio arquitectónico. La combinación e interrelación de esta clase de textos depende de los medios y modos, a su vez, del tiempo y espacio concretos donde se producen y donde se utilizan, como propusieron las teóricas del letramento.

En el siguiente apartado se ejemplificará la comunicación multimodal con una clase de objetos no considerados comúnmente como escritura; pero que, asumiendo la argumentación anterior, adquieren un sentido distinto a los ojos del investigador y que para el maestro alfabetizador abre posibilidades pedagógicas sugerentes. La apuesta por una alfabetización multimodal en perspectiva decolonial debe reconocer que estos lenguajes tienen toda una complejidad cultural, cuya comprensión tiene la potencia de develar un sentido trascendente, en oposición a la superficialidad en la cual incurren las industrias creativas y culturales impulsadas por la Unesco (Unesco, 1996, 2003, 2010; Žižek y Jameson, 1998); tal proceso puede hacerse con toda legitimidad mediante proyectos de alfabetización no excluyente cuya función es contener la violencia simbólica aparejada al prejuicio grafocéntrico. 


\section{DECOLONIZAR LA ALFABETIZACIÓN}

En este último apartado se mostrará que, ampliado el concepto de escritura y de cultura escrita (generalmente asociado a lo estrictamente alfabético) hacia el de prácticas de escritura, puede avizorarse un horizonte de opciones variadas a la hora de encarar proyectos de alfabetización decolonial. Haciendo uso de la teoría multimodal del discurso, el corpus del siglo XXI para analizar el lenguaje adquiere una característica fundamental: la no linealidad. Cualquier estudio encauzado a moverse en el terreno de las multialfabetizaciones debe tener en cuenta que en el siglo XX se proponen una serie de nuevas miradas sobre los datos que servirán para extraer regularidades y continuidades, para formular teorías sobre fenómenos lingüísticos y semióticos. En otras palabras:

queremos enfocar la investigación empírica sistemática en nuestros campos en forma más dinámica, como la operación simultánea e impredecible de procesos que convergen y divergen en una constante oscilación entre equilibrio, casi desequilibrio y desequilibrio, entre simplificación, normalización y diversificación. En otras palabras, ya no queremos descartar como puro "ruido" la parte de nuestros datos que no se ajuste a esquemas lineales y unidireccionales diseñados para explicar un proceso lógico de cambio o evolución (Williamson, 2007, p. 209).

No se debe olvidar que:

No podemos utilizar una escritura para caracterizar una lengua; la escritura es un componente claramente cultural que se utiliza, como ocurre con la lengua oral o gestual, no solo para comunicar información, sino también para caracterizar y mostrar nuestra individualidad social y cultural y para diferenciarnos de, o identificarnos con, los demás cultural o religiosamente (Moreno, 2005, p. 10).

Durante la época de la Colonia, la noción alfabética de la escritura en el imperio español impidió ver cualquier producción escrita indígena al identificar estas con lo artificioso y lo estrictamente oral:

Se dice frecuentemente que las culturas indígenas del ámbito andino son culturas orales. Con ello se quiere hacer referencia a la fuerza de la comunicabilidad, por parte de sus hablantes, en el desempeño oral y no en la tradición escrita. Esta afirmación tiene bastante de cierto pero también es reduccionista (Garcés y Sánchez, 2014, p. 13).

Esta situación puso límite a las observaciones de los estudiosos sobre la relevancia de los datos, pues los parámetros de entonces (y aún de ahora) debían parecerse a la producción alfabética establecida. El español José de Acosta, encargado por la Corona para el estudio de las culturas indígenas, por ejemplo, no consideró los khipus como escritura, pues carecían de caracteres alfabéticos; aunque, básicamente, cumplían las mismas funciones sociales, según sus propias descripciones. La gente de la denominada "alta cultura" en ese entonces no asociaba la escritura a cosa distinta de signos alfabéticos marcados sobre una superficie de papel, mientras los khipus mantuvieron su función en la marginalidad de la "baja cultura" (Garcés y Sánchez, 2014); en consecuencia, la definición y las implicaciones culturales de la escritura siguieron este curso en el establecimiento de la diferenciación social entre etnias, que todavía son visibles hoy. Es importante recordar que Acosta, al igual que los intelectuales de su época, no tenía un concepto positivo del grabado, el dibujo o la pintura, pues esa clase de libros era para gente de poca valía, brutos y legos; las ilustraciones y el material pictográfico, para la Europa de entonces, cumplían una simple función decorativa (Kress, 2005). Desde luego se creyó que los tejidos andinos tenían una función únicamente mnemotécnica y no servían más que como material de apoyo para memorizar el catecismo. Sin embargo, esta tesis solo fue reconsiderada hasta la emergencia de la antropología moderna. 
En 1911, Franz Tamayo decodificó un cuero encontrado en el lago Titicaca mediante el mismo sistema aplicado a la escritura azteca; el resultado arrojó que se trataba de algunos rezos cristianos renarrados en el lenguaje y la mitología propias de la tribu, pero codificadas en su particular escritura ideográfica. De ello se deduce que no cumplía solo una función meramente mnemotécnica, pues sus rasgos poseen una autonomía propia. Dick Ibarra, en 1953, realiza una cartografía de esta escritura en Bolivia y recoge una gama de materiales (modos tales como cuero, barro y papel) que ahora se encuentran en una colección del Instituto de Investigaciones Antropológicas y Museo de la Universidad Mayor de San Simón en Cochabamba (Garcés y Sánchez, 2014).

Estos elementos suscitan dos problemas para los investigadores: primero "dilucidar si es posible hablar de una auténtica escritura en referencia a la escritura ideográfica mostrada; en segundo, si estas ideografías constituyen algún tipo de evidencia sobre una posible tradición prehispánica" (Garcés y Sánchez, 2014, p. 34). Investigadores como Mitchel y Jaye insisten en que la escritura andina es un técnica auxiliar de memorización; otros como Mariño, Vich y Zavala y Street se inclinan a pensar que la escritura no viene dada de antemano y que sus usos son más bien relativos, razón por la cual no podría hablarse de un solo tipo de escritura, pues no existen leyes universales al respecto. En conclusión, lo que estaría en juego en este punto es el descubrimiento de un tipo de escritura oculta a los ojos de los investigadores en el seno de la disciplina de las ciencias del lenguaje, pues aún no se habría dado el cambio de paradigma necesario para observar estos objetos con otros ojos y darles su justo lugar (Garcés y Sánchez, 2014); aunque basta advertir que "si observamos la distribución de los sistemas de escritura hacia la segunda mitad del siglo XX, podremos comprobar que el alfabeto romano está implantado en gran parte del mundo" (Moreno, 2005, p. 47) y seguirá siendo difícil apartar la vista de la grafía.

La ruptura con este pensamiento hegemónico implica entender cómo la tradición educativa institucionalizada siempre ha tenido como referente teleológico una idea de modelo pedagógico: el maestro necesita pensar cómo debe ajustar su práctica concreta para conseguir aquello que se espera de la educación, pues los objetivos ya están determinados por el Estado o las corporaciones que financian la formación del estudiantado. Por su parte, la pedagogía decolonial va de la mano de los movimientos de resistencia mismos, de las carencias y las necesidades; por ello no se mide con relación a un ideal abstracto universalmente válido, sino que parte de la experiencia sensible de las personas.

Las pedagogías pensadas así no son externas a las realidades, subjetividades e historias vividas de los pueblos y de la gente, sino parte integral de sus combates y perseverancias o persistencias, de luchas de concientización, afirmación y desalineación, y de sus bregas -ante la negación de su humanidad- de ser y hacerse humano (Walsh, 2013, p. 31).

Por lo tanto, la educación intercultural se da de manera contingente y ello exige dar cuenta de sus lenguajes con teorías igualmente flexibles, incluyentes y dialógicas como lo hace la teoría de las multialfabetizaciones: en el caso anterior, poder inventariar ese sistema de escritura ocultado en el tiempo y estudiarlo en las escuelas como parte del reconocimiento de la pluralidad étnica de los pueblos americanos. En otras palabras, alfabetizar contemporáneamente no puede identificarse solamente con la decodificación de un sistema alfabético de signos gráficos o el manejo eficiente de las computadoras; en sociedades interculturales como las latinoamericanas es preciso negociar el significado a través de diversos lenguajes, y la educación es un pretexto para propiciarlo mediante su recreación y estudio. Solamente de esta manera una pintura dejará de ser una simple copia de realidad empírica o una experimentación abstracta, la fotografía adquirirá su fuerza como un arte, un libro dejará de ser un simple depositario del saber y las formas de un vestido andino dejarán de ser ornatos para mostrar 
en celebraciones folclóricas especiales que nadie comprende. Todo esto posee un sentido para significar la tradición, que como dice Walter Benjamin, se inscribe dentro de unos ritos y unos sentires vitales que nos tocan a todos como comunidad cuya actualidad es vigente y palpitante en la realidad social.

\section{CONCLUSIONES}

Una de las maneras de descentralizar el discurso sobre la alfabetización grafocéntrica es propiciar el reconocimiento de los lugares de enunciación en las propuestas formativas; para estas pretensiones, el esquema propuesto por la pedagogía de las multialfabetizaciones satisface las condiciones necesarias. La alfabetización multimodal reconoce el papel estratégico de la educación en las comunidades cuando dota a los discursos de fuerza expresiva y de potencia performativa adecuados a sus respectivos fines sociales; efectos entre los cuales podemos contar la censura o la alabanza de conductas y valores que nos atraviesan en la cotidianidad; búsqueda de adhesión a una postura política o generación de rechazo frente a otra cuando los sujetos tienen el deber ciudadano de decidir.

Dichos discursos generalmente están encarnados en toda la gama de medios materiales a disposición de las personas, y aprender a utilizarlos es un compromiso cuando se quieren hacer buenas elecciones: la educación se encarga de analizar los formatos en los cuales se maneja la información, lo que implica saber dónde, cómo y cuándo extraerla para manipularla en situaciones concretas de manera responsable y crítica. Las multialfabetizaciones son, en resumidas cuentas, una actitud receptiva a la infinidad de textos multimodales que nos atraviesan a diario.

Debido a la maleabilidad de los modos y los discursos, es utópico proponer una solución imperecedera y terminantemente acabada sobre la alfabetización. Como se ha visto, la alfabetización universal como solución para todos los males sociales (en el transcurso del siglo XX) ha implosionado desde el punto de vista científico: la semiótica social demolió, con su propuesta de los niveles del lenguaje (textual, ideativo e interpersonal), las esperanzas que la alfabetización tradicional tenía de satisfacer todas las necesidades explicativas sobre el lenguaje humano; y la emergencia del discurso, como nueva unidad de significado, evidenció las falencias de la enseñanza del lenguaje limitada a los niveles fonológico y morfosintáctico. Por otro lado, desde el punto de vista social, su expansión a las clases menos favorecidas no significó una mayor democratización del acceso a la educación, la salud o el empleo; por el contrario, ahondó las diferencias entre las culturas letradas y las no letradas al normalizar como política de Estado unas prácticas particulares obligadas para toda la población.

\section{RECONOCIMIENTOS}

El presente artículo es un avance de la investigación en proceso titulada "La escritura creativa y el discurso multimodal en el contexto escolar", iniciada en octubre de 2014 y actualmente en curso, la cual se desarrolla en el grupo de investigación LECME (Lenguaje, Cultura y Medios), adscrito a la Universidad Distrital Francisco José de Caldas.

\section{REFERENCIAS}

Bautista, A. (2007). Alfabetización tecnológica multimodal e intercultural. Revista de Educación, 343, 589600. Universidad Complutense de Madrid.

Bawden, D. (2008). Origins and concepts of digital literacy. En C. Lankshear y M. Knobel (Eds.) Digital Literacies: Concepts, Policies and Practices (pp. 18-45). New York: Peter Lang Publishing.

Castro-Gómez, S. y Grosfoguel, R. (2007). Prólogo. Giro decolonial, teoría crítica y pensamiento heterárquico. En Autores (Eds.). El giro decolonial. Reflexiones para una diversidad epistémica más allá del capitalismo global (pp. 9-24). Bogotá: Siglo del Hombre Editores.

Ferreiro, E. (2005). Pasado y presente de los verbos leer y escribir ( $2^{\mathrm{a}}$ reimp.). México D. F.: Fondo de Cultura Económica. 
Garcés, F. y Sánchez, W. (2014). La colección de escrituras ideográficas andinas del Instituto de Investigaciones Antropológicas y Museo de la Universidad Mayor de San Simón INIAM-UMSS: una forma de narrar sin letras. Estudio introductorio. En Escritura andina. Pictografía e ideografía en cuero y papel (pp. 11-38). Universidad Mayor de San Simón: Cochabamba.

González, J. (2013). Alfabetización multimodal: usos y posibilidades. Campo Abierto, 32(1), 91-113.

Hernández, G. (2008). Alfabetización: teoría y práctica. Decisio, Saberes para la acción en educación de adultos, 21, 18-24.

Hull, G. y Hernández, G. (2008). Literacy. En F. Hult y B. Spolsky (Eds.), The Handbook of Educational Linguistics (pp. 328-340). Singapore: Blackwell Publishing.

Kress, G. (2005). El alfabetismo en la era de los nuevos medios de comunicación. Málaga: Ediciones Aljibe.

Manghi, D. (2007). Enseñanza del uso de la lengua en la escuela. Reflexiones acerca de la lingüística aplicada a la educación. En Actas del XVII Congreso SOCHIL, Investigación y Enseñanza de la Lingüística. [En línea]. Recuperado de https://brochagorda. files.wordpress.com/2008/07/acta-sochil-d-manghi-h2.pdf

Manghi, D. (2011). La perspectiva multimodal sobre la comunicación. Desafíos y aportes para la enseñanza en el aula. Revista Electrónica Diálogos Educativos, 11(25), 3-14. [En línea]. Recuperado de http:// www.redalyc.org/pdf/2431/243129663005.pdf

Manghi, D., González, D., Echeverría, E., Marín, C., Rodríguez, P., y Guajardo, V. (2013). Leer para aprender a partir de textos multimodales: los materiales escolares como mediadores semióticos. REXE: Revista de Estudios y Experiencias en Educación, 12(24), 77-91. Universidad Católica de la Santísima Concepción, Chile.

Manovich, L. (2005). El lenguaje de los nuevos medios. La imagen en la era digital. Barcelona: Paidós.
Moreno, J. C. (2005). Las lenguas y sus escrituras: tipología, evolución e ideología. Madrid: Síntesis.

New London Group. (1996). A pedagogy of multiliteracies: Designing social futures. Harvard Educational Review, 66 (1), 60-92.

Olson, D. (1998). El mundo sobre el papel. El impacto de la escritura y la lectura en la estructura del conocimiento. Barcelona: Gedisa.

Pardo, N. (2012). Discurso en la web: pobreza en Youtube. Universidad Nacional de Colombia: Bogotá.

Soares, M. (1998). Letramento: um tema en três gêneros. Belo Horizonte: Autêntica.

Soares, M. (2004). Letramento y alfabetização: as muitas facetas. Revista Brasileira de Educação, 25, 5-17.

Street, B. (2009). Ethnography of writing and reading. En D. Olson y N. Torrance, (Eds.), The Cambrigde Handbook of Literacy (pp. 329-343). New York: Cambrigde University Press.

Unesco. (2010). Políticas para la creatividad. Guía para el desarrollo de industrias culturales y creativas. Buenos Aires.

Unesco. (2003). Declaración Universal sobre la Diversidad Cultural. Lima.

Unesco. (1996). Nuestra diversidad creativa. Informe de la Comisión Mundial de Cultura y Desarrollo (versión resumida). París.

Walsh, C. (2013). Lo pedagógico y lo decolonial. Entretejiendo caminos. En Autor (Ed.), Pedagogías decoloniales. Prácticas insurgentes de resistir, (re)existir y (re) vivir, tomo I. Quito: Abya Yala.

Williamson, R. (2005). ¿A qué llamamos discurso en una perspectiva multimodal? Los desafíos de una nueva semiótica. En América Latina en su discurso. Actas del VI Congreso Latinoamericano de Estudios del Discurso. [En línea]. Recuperado de https://es.scribd.com/ doc/55750982/Williamson-Dis-Cur-So-Multi-Modal

Williamson, R. (2007). El diseño de un corpus multimodal. Revista Estudios de Lingüística Aplicada, 46, 207231. Unam.

Žižek, S. y Jameson, F. (1998). Estudios culturales. Reflexiones sobre el multiculturalismo. Buenos Aires: Paidós.

\section{(9) $(1) \Theta \Theta$}

